\title{
A TUTELA DOS CORPOS PELO ESTADO E A PRODUÇÃO DO CORPO SEM ÓRGÃOS: COMO GANHAR TERRENO A PARTIR DOS DIREITOS DA PERSONALIDADE
}

Caio Hoffmann Cardoso Zanon ${ }^{1}$

Resumo: O objetivo deste artigo é o questionamento da atual regulamentação dos direitos da personalidade pelo Código Civil de 2002 à luz da teoria de Deleuze e Guattari sobre o corpo sem órgãos. Como método, utiliza-se de uma análise primeiro da lei e, em seguida, da principal proposta que se tem nos dias atuais para uma reinterpretação do regime dos direitos da personalidade, que seria a doutrina Civil-constitucional, a partir do marco teórico proposto. Como conclusão, chega-se à afirmação de que tanto a regulamentação do Código Civil como a proposta Civil-constitucional não têm êxito em acolher de forma plena a multiplicidade, pois permanecem ligadas à ideia de indivíduo em vez de a uma visão que privilegie os fluxos e intensidades que passam pelos corpos. Propõem-se pesquisas futuras no que diz respeito a formas de desestratificação dos corpos e à identificação de deformações anárquicas no texto constitucional que possibilitem uma realidade acolhedora da diversidade.

Palavras-chave: tutela dos corpos; multiplicidade; direitos da personalidade.

\section{Introdução}

O objetivo deste trabalho é analisar o regime dos direitos da personalidade atualmente em vigor no ordenamento jurídico brasileiro tendo como marco teórico o pensamento de Gilles Deleuze e Félix Guattari sobre o corpo sem órgãos. Isso porque a forma como a pessoa é disciplinada pelo atual Código Civil é altamente controversa, abrindo brechas consideráveis para que o Estado - e os interesses hegemônicos que representa - ditem o que será feito dos corpos. Propõe-se, então, a partir deste marco teórico, que propõe a desestratificação da subjetivação, da significância e do organismo, um novo olhar sobre os corpos que os permita serem efetivamente livres e diversos.

Em um primeiro momento, discorre-se, a título de contextualização, sobre as ideias de Foucault acerca do corpo e do poder. Depois é apresentada a teoria de Deleuze e Guattari acerca do corpo sem órgãos, que propõe a produção de um corpo que não tenha o funcionamento submetido a uma forma previamente definida por poderes hegemônicos - o que os autores chamam de organismo - , mas que, do contrário, possa produzir e fazer passar por ele de forma livre as intensidades.

\footnotetext{
${ }^{1}$ Graduando em Direito na Universidade Federal de Juiz de Fora (UFJF).

Endereço eletrônico para contato: <caiohoffmann@ymail.com>.

CSOnline - Revista Eletrônica de Ciências Sociais, Juiz de Fora, n. 24 (2017) Dez., pp. 1-309.
} 
Em seguida, apresenta-se o modo como estão conformados os direitos da personalidade no Código Civil de 2002, criticando-se ainda as disposições que os disciplinam e fazendo ver como elas colocam nas mãos do Estado e dos saberes médicos as decisões que dizem respeito aos corpos.

No momento posterior, passa-se à exposição da crítica do direito Civilconstitucional em relação à regulação dos direitos da personalidade pelo Código Civil de 2002. Essa corrente do Direito propõe que o Código e as disposições sobre direitos da personalidade nele contidas, sejam reinterpretados à luz dos princípios constitucionais, mormente o da dignidade humana, que serviria como uma cláusula geral de tutela da pessoa a guiar as decisões a serem tomadas pelo Estado no que diz respeito aos direitos da personalidade.

Em um momento final, ainda, faz-se uma crítica tanto ao que está disposto no Código Civil quanto à reinterpretação Civil-constitucional, problematizando a noção de indivíduo com a qual a reinterpretação não foi capaz de romper e identificando nela os estratos do organismo, da significância e da subjetivação, característicos de corpos bloqueados pelos quais não conseguem passar livremente as intensidades. Propõe-se, assim, um novo modo de se ver as coisas, em que os indivíduos sejam unidades secundárias em relação às intensidades e aos fluxos, esses sim os elementos primários, que encontrariam, durante seus percursos, as unidades-indivíduo. Defende-se, ainda, a procura de deformações anárquicas no texto constitucional para que se faça a partir dele algo acolhedor da diversidade que permita o desenvolvimento seguro dos corpos sem órgãos.

\section{Poder disciplinar e biopoder: o corpo em Foucault}

É proveitoso, antes de entrar no marco teórico propriamente dito, ou seja, o pensamento de Deleuze e Guattari em relação ao corpo sem órgãos, mencionar sucintamente algumas ideias de Michel Foucault sobre o corpo e os poderes que atuam sobre ele. Isso porque Deleuze e Guattari foram alunos de Foucault e, por isso, certamente o pensamento deste foi importante para que aqueles começassem a pensar suas teorias.

Apesar de não haver na obra de Foucault uma definição explícita de corpo, Mendes (2006, p. 2) afirma que o filósofo o concebe como um ente material que preexiste enquanto superfície, mas que é moldável através de técnicas de disciplina e biopolítica enquanto "objeto de relações de poder-saber que constituem atitudes corporais e formas de sujeito" (MENDES, 2006, p. 2). 
Foucault procura, então, esquadrinhar a concretude do exercício do poder sobre o corpo, pensando de que maneira esse poder é exercido para que haja a manutenção da sociedade capitalista. $\mathrm{O}$ autor, ainda, não foca na questão da ideologia, que já pressupõe o sujeito humano modelo que estabelece a filosofia clássica, mas sim na questão dos efeitos do poder sobre o corpo para que ele se amolde à ideia de sujeito e para que essa ideia apareça como dada (FOUCAULT, 1979, p. 147-148). Ressalta-se, ainda, que Foucault não concebe o poder como concentrado no aparelho estatal e sim disseminado e se exercendo a partir de vários mecanismos localizados a um nível mais "cotidiano" da vida das pessoas. O autor não descarta a importância do Estado, mas coloca que limitar o estudo do poder ao âmbito dele seria também ter uma compreensão limitada e ineficaz do funcionamento de seus mecanismos (FOUCAULT, 1979, p. 149-150).

A análise foucaultiana do exercício do poder sobre o corpo foca-se, sobretudo, no poder disciplinar, de um lado, e no biopoder e na biopolítica, de outro. Essas duas formas do exercício do poder estão em níveis diferentes e vêm articuladas (FOUCAULT, 1999, p. 299), sendo que a primeira se exerce a nível individual e a segunda a nível populacional. A diferenciação entre elas é feita por Foucault (1999, p. 297) de maneira a entendê-las como

duas tecnologias de poder que são introduzidas com certa defasagem cronológica e que são sobrepostas. Uma técnica que é, pois, disciplinar: e centrada no corpo, produz efeitos individualizantes, manipula o corpo como foco de forças que é preciso tomar úteis e dóceis ao mesmo tempo. E, de outro lado, temos uma tecnologia que, por sua vez, e centrada não no corpo, mas na vida; uma tecnologia que agrupa os efeitos de massas próprios de uma população, que procura controlar a série de eventos fortuitos que podem ocorrer numa massa viva; uma tecnologia que procura controlar (eventualmente modificar) a probabilidade desses eventos, em todo caso em compensar seus efeitos. É uma tecnologia que visa portanto não o treinamento individual, mas, pelo equilíbrio global, algo como uma homeostase: a segurança do conjunto em relação aos seus perigos internos.

São esses alguns dos pontos cruciais do pensamento de Foucault envolvendo o corpo. Esses pontos seriam inspirações para que, mais tarde, Deleuze e Guattari começassem a teorizar a multiplicidade, os fluxos e os corpos, não de maneira idêntica a Foucault, mas num caminho bastante sincronizado.

\section{O corpo sem órgãos para Deleuze e Guattari}

Servirá como marco teórico, para este artigo, a ideia de Deleuze e Guattari (1996) quanto ao corpo sem órgãos como forma de libertação dos corpos do funcionamento imposto a eles pelo Estado e pelas relações de poder num geral. Os autores defendem que se desestratifiquem os corpos que, sob a tutela estatal, ficam restritos a um modo de funcionamento específico que lhes é imposto, chamado por eles de "organismo". 
"O CsO é o que resta quando tudo foi retirado. E o que se retira é justamente o fantasma, o conjunto de significâncias e subjetivações”, dizem Deleuze e Guattari (1996, p. 12) em um dos textos de seus Mil Platôs. O corpo sem órgãos, que não é um conceito e sim um conjunto de práticas (DELEUZE; GUATTARI, 1996, p. 9), é uma forma de entender os corpos realmente acolhedora da multiplicidade. Esse corpo não possui conteúdo definido e em seu interior só podem existir intensidades que ele mesmo produz e que faz passar. Nele, os órgãos não têm posições e funções pré-definidas, podendo existir, mas em constante movimento e transformação, funcionando como "intensidades puras". É diferente, portanto, da ideia de organismo, na qual se tem um encadeamento de órgãos que funcionam de uma maneira específica (DELEUZE; GUATTARI, 1996, p. 1314).

O corpo sem órgãos não é um fim, mas uma prática constante, um limite que não se pode atingir, mas no qual se pode estar (DELEUZE; GUATTARI, 1996, p. 9-10). Desse modo, entende-se que a produção do corpo sem órgãos passa por uma desestratificação, já que esse corpo exige inúmeros estratos conectados uns aos outros, não podendo ficar restrito a nenhum e nem a um conjunto deles. Para a produção do corpo sem órgãos, ou seja, esse constante conjunto de práticas que visa a desestratificar o corpo, três noções a serem combatidas são a de organismo, a de subjetivação e a de significância (DELEUZE; GUATTARI, 1996, p. 22). O organismo seria onde são operadas a significação e a subjetivação, sendo que os corpos que não se limitam a essa lógica e que não estão restritos a um conjunto de estratos, na sociedade atual, são tidos como desviantes. Contra essa noção é proposta a desarticulação dos estratos onde se operam esses processos que bloqueiam a passagem de intensidades pelo corpo, opondo-se a eles um plano de consistência em que nada é interpretado e que permite a passagem dessas intensidades (DELEUZE; GUATTARI, p. 22). Esse plano, que se constrói lentamente, seria um conjunto de todos os corpos sem órgãos se comunicando sob o mesmo plano e se movimentando de forma a operar uma desterritorialização (DELEUZE; GUATTARI, 1996, p. 19). Sobre a significância, diz que ela "cola na alma assim como o organismo cola no corpo", estando associada a essa noção de dar um sentido às coisas, e que a ela deve se opor um movimento constante, uma recusa a interpretar algo, privilegiando a ideia de produção (DELEUZE; GUATTARI, 1996, p. 22). Finalmente, quanto à subjetivação, ela seria resumidamente a construção do "eu" e a restrição ao sujeito, em razão do que Deleuze e Guattari (1996, p. 22) entendem que a sua derrubada passaria pelo ato de "arrancar a consciência do sujeito para fazer dela um meio de exploração". Desse CSOnline - Revista Eletrônica de Ciências Sociais, Juiz de Fora, n. 24 (2017) Dez., pp. 1-309. 
modo, ao se retirar a restrição do estrato da subjetivação, o corpo está apto a se abrir às mais diversas intensidades, o que antes não lhe era permitido em função desse bloqueador. Quanto a isso, como afirmam Deleuze e Guattari (1996, p. 11), "onde a psicanálise diz: Pare, reencontre o seu eu, seria preciso dizer: vamos mais longe, não encontramos ainda nosso CsO, não desfizemos ainda suficientemente nosso eu".

Passa-se, em seguida, ao que dizem os autores quanto ao processo de produção do corpo sem órgãos, principalmente frente ao império do organismo que se tem arraigado na atualidade. Deleuze e Guattari defendem que essa produção, que passa pela desestratificação dos três estratos mencionados acima, deve ser marcada pela prudência. O desfazimento do organismo não pode ser abrupto ou descuidado, caso em que se tem a influência de impressões falsas ou ilusórias e em que se pode chegar a "tangenciar a morte". Do contrário, deve-se produzir o corpo sem órgãos para identificar quando as impressões são ou não ilusórias, podendo levar à ruína do corpo. O caminho não é se livrar do organismo todo de uma vez, mas manter consigo um pouco dele de modo que se possa continuar e não perecer, e até mesmo de modo a poder questionar a própria realidade vigente (DELEUZE; GUATTARI, 1996, p. 23).

Assim, Deleuze e Guattari atestam, sobre o modo indicado de se produzir o corpo sem órgãos:

Havia mesmo várias maneiras de perder seu CsO, seja por não se chegar a
produzi-lo, seja produzindo-o mais ou menos, mas nada se produzindo sobre
ele e as intensidades não passando ou se bloqueando. Isso porque o CsO não
pára de oscilar entre as superfícies que o estratificam e o plano que o libera.
Liberem-no com um gesto demasiado violento, façam saltar os estratos sem
prudência e vocês mesmos se matarão, encravados num buraco negro, ou
mesmo envolvidos numa catástrofe, ao invés de traçar o plano. O pior não é
permanecer estratificado - organizado, significado, sujeitado - mas
precipitar os estratos numa queda suicida ou demente, que os faz recair sobre
nós, mais pesados do que nunca. Eis então o que seria necessário fazer:
instalar-se sobre um estrato, experimentar as oportunidades que ele nos
oferece, buscar aí um lugar favorável, eventuais movimentos de
desterritorialização, linhas de fuga possíveis, vivenciá-las, assegurar aqui e ali
conjunções de fluxos, experimentar segmento por segmento dos contínuos de
intensidades, ter sempre um pequeno pedaço de uma nova terra. É seguindo
uma relação meticulosa com os estratos que se consegue liberar as linhas de
fuga, fazer passar e fugir os fluxos conjugados, desprender intensidades
contínuas para um CsO (DELEUZE; GUATTARI, 1996, p.23-24).

Esse, em suma, é o pensamento de Deleuze e Guattari acerca do corpo sem órgãos, aberto para as intensidades, inimigo do organismo e não dos órgãos (DELEUZE; GUATTARI, 1996, p. 21), noção libertária de corpo. Esse entendimento será, agora, usado de marco teórico para a análise dos direitos da personalidade no Código Civil de 2002 e de uma das suas propostas de reinterpretação, com o objetivo de mostrar como a lei, nesse caso, funciona como um dos muitos propagadores dos corpos bloqueados. 


\section{Os direitos da personalidade no Código Civil de 2002}

Os direitos da personalidade são tradicionalmente classificados como direitos subjetivos privados, ou seja, posições titularizadas pelos sujeitos de direito quando se diz respeito às relações entre particulares (TEPEDINO, 1999, p. 33). Esses direitos visam a tutelar a própria pessoa humana, sendo considerados pelo Direito inerentes à condição humana, tutelando-a tanto individualmente, no sentido da garantia de uma existência livre, como coletivamente, no sentido da tutela das relações entre particulares (TEPEDINO, 1999, p. 24).

Esses direitos ganharam destaque quando se percebeu que não só as relações entre indivíduo e Estado, mas também entre indivíduos, carregavam assimetrias e precisavam ser reguladas para evitar violações. Assim, criou-se a ideia de que os direitos da personalidade seriam semelhantes aos "direitos humanos", mas, enquanto estes serviriam na tutela da relação indivíduo-Estado, aqueles ajudariam a regular as relações entre os indivíduos para proteger a pessoa humana (TEPEDINO, 1999, p. 33).

É importante ressaltar que os direitos patrimoniais serviram de molde à formação da concepção sobre os direitos da personalidade, por isso o seu regime apresenta uma forte marca patrimonialista (TEPEDINO, 1999, p. 30), sendo eles derivados mormente do direito à propriedade. Desse modo, dota-se os direitos da personalidade de generalidade - eficácia erga omnes - e outras características como imprescritibilidade, intransmissibilidade e indisponibilidade (TEPEDINO, 1999, p. 33).

No Código Civil de 2002, atualmente em vigor no ordenamento jurídico brasileiro, os direitos da personalidade são regulados em capítulo próprio, o II do Livro I e Título I, que apresenta inclusive um rol exemplificativo desses direitos. O Código Civil adotou a classificação explicitada acima, inclusive os atributos de intransmissibilidade e indisponibilidade dos direitos, no art. 11 (BRASIL, 2002).

São várias as críticas que podem ser tecidas aos direitos da personalidade como um todo e como regulados pelo Código Civil de 2002. Serão expostas, agora, algumas delas, a partir dos respectivos dispositivos legais em que se encontrarem disciplinados os pontos criticados.

A principal crítica à maneira como são disciplinados os direitos da personalidade no nosso Código Civil diz que essa disciplina seria feita de forma que engessa o exercício desses direitos. Isso porque, ao dispor sobre a indisponibilidade e intransmissibilidade deles no artigo 11, o Direito pode acabar cerceando indevidamente a ingerência do indivíduo em relação ao seu próprio corpo. Diz o artigo 11 (BRASIL, 2002) que "com CSOnline - Revista Eletrônica de Ciências Sociais, Juiz de Fora, n. 24 (2017) Dez., pp. 1-309. 
exceção dos casos previstos em lei, os direitos da personalidade são intransmissíveis e irrenunciáveis, não podendo o seu exercício sofrer limitação voluntária". A impossibilidade de renunciar ou de transferir esses direitos pode resultar em situações em que o corpo do indivíduo seja regulado pelo Estado e não pela sua própria vontade. Apesar de a regulação nesse caso ter sido feita pensando em proteger os indivíduos de assimetrias (SILVA, 2016) e lhes assegurar o gozo de seus direitos, nem sempre haverá situação assimétrica. Enxerga-se, aqui, um claro esforço estatal para dizer como devem ser ou não os corpos dos que vivem sob seu poder. Essa leitura é reafirmada pelos artigos 13 e 14 do mesmo Código (BRASIL, 2002):

Art. 13. Salvo por exigência médica, é defeso o ato de disposição do próprio corpo, quando importar diminuição permanente da integridade física, ou contrariar os bons costumes.

Parágrafo único. $\mathrm{O}$ ato previsto neste artigo será admitido para fins de transplante, na forma estabelecida em lei especial.

Art. 14. É válida, com objetivo científico, ou altruístico, a disposição gratuita do próprio corpo, no todo ou em parte, para depois da morte.

Parágrafo único. $\mathrm{O}$ ato de disposição pode ser livremente revogado a qualquer tempo.

Esses dois artigos trazem várias situações problemáticas. $\mathrm{O}$ artigo 13 impede explicitamente que o indivíduo disponha de seu próprio corpo de forma permanente, numa situação que, mais uma vez, é colocada para proteger o indivíduo em caso de situações assimétricas, mas que pode acabar, na verdade, impondo os interesses do Estado sobre o corpo do indivíduo. Além disso, coloca-se a proibição de disposição do corpo que contrarie os "bons costumes”, expressão extremamente problemática já que é impossível definir de forma justa quais costumes são esses, ficando evidente que serão levados em conta os costumes dos grupos que possuem poder econômico e político e que estão em posição de tomar decisões envolvendo esse artigo no âmbito estatal. Por fim, tanto o artigo 13 como o artigo 14 trazem ressalvas em relação à ciência e, mais especificamente, à medicina, permitindo a disposição do próprio corpo para fins científicos ou se houver autorização de algum médico. Coloca-se, então, o poder sobre o corpo do indivíduo nas mãos do saber médico. $\mathrm{O}$ artigo 14 permite essa disposição após a morte, respeitando aqui a "vontade do indivíduo". Enquanto isso, o artigo 12, parágrafo único, permite ao cônjuge ou a alguns parentes que exijam judicialmente cessão a direito da personalidade de morto, requisitando até mesmo perdas e danos. É pertinente, diante dessa situação, demandar: por que não se pensou em proteger a pessoa humana de possíveis assimetrias frente à autoridade médica? É claro que, conforme o artigo 16, por exemplo, ninguém pode ser constrangido a se submeter a tratamento médico, mas a questão é que, a partir do 
momento em que se tem o aval médico, o corpo se torna disponível, enquanto que sem esse aval ele não está disponível hora nenhuma.

É claro que não se está a defender, neste artigo, a soberania e a intangibilidade de uma pretensa autonomia da vontade, nem se está a dizer que se crê que não sejam a maioria das decisões na sociedade atual tomadas sem nenhuma "autonomia". O que se está tentando mostrar é que essa tentativa de proteger o corpo do indivíduo está cheia de problemas e precisa ser repensada de forma que os corpos parem de ser espremidos pelos poderes econômicos e políticos em moldes de organismos pelos quais as intensidades não podem circular. A regulação dos direitos da personalidade no Código Civil brasileiro de 2002 precisa, então, ser repensada ou reinterpretada, conforme se verá em seguida.

\section{A crítica feita pelo direito civil-constitucional}

Apesar de ser o advento dos direitos da personalidade um sinal de uma maior preocupação das relações entre os indivíduos, viu-se acima o quão problemática é a regulação que se tem desses direitos. Parte desse problema é atribuída ao fato de que a disciplina dos direitos da personalidade foi feita nos moldes da regulação de relações patrimoniais, sendo que o objeto é a tão complexa pessoa humana, incapaz de ser capturada por categorias patrimoniais (TEPEDINO, 1999, p. 45). Esse problema pode ser remetido, em última instância, a um problema mais geral no Direito Civil e nas codificações, que diz respeito à insuficiência das categoriais elaboradas quando de seu surgimento, marcadas pelo voluntarismo e pelo individualismo, para enfrentar as questões mais complexas que têm aparecido nos últimos tempos no âmbito do "Direito Privado" (TEPEDINO, 2004, p. 2 e 6). Isso aconteceu concomitantemente a uma maior regulação das relações privadas pelo texto constitucional, com a Constituição de 1988, além de um maior protagonismo de uma legislação extracodificada, que não mais estava focada no indivíduo mas sim nas atividades específicas desenvolvidas sob o âmbito de regulação de cada lei (TEPEDINO, 2004, p. 7). O Código Civil perde, desse modo, sua posição central no Direito Privado.

Diante desse quadro, muitos juristas começaram a defender o que se chama de eficácia horizontal dos direitos fundamentais. Segundo essa teoria, os direitos fundamentais, que são os direitos humanos incorporados às legislações dos países, não mais se restringiriam, nesse novo quadro apresentado, a uma regulação das relações indivíduo-Estado, mas que também teriam influência nas relações entre particulares. A Constituição seria, desse modo, o texto que serviria como unificador de um Direito Civil fragmentado em várias legislações específicas e com um Código que não mais assume CSOnline - Revista Eletrônica de Ciências Sociais, Juiz de Fora, n. 24 (2017) Dez., pp. 1-309. 
nele posição central. Surge, assim, o que se chama de doutrina do Direito Civilconstitucional.

Gustavo Tepedino (2004) afirma que o Direito Civil, atualmente, deve ser reinterpretado a partir das normas fundamentais da Constituição, principalmente a partir do princípio da dignidade humana, já que há uma opção do constituinte por intervir nas relações privadas. Pede-se, assim, o abandono da divisão estanque que vigorava entre Direito Público e Direito Privado (TEPEDINO, 2004, p. 19). É nesse sentido que o autor afirma pensar ser necessário

estabelecer novos parâmetros para a definição de ordem pública, relendo o direito civil à luz da Constituição, de maneira a privilegiar, insista-se ainda uma vez, os valores não-patrimoniais e, em particular, a dignidade da pessoa humana, o desenvolvimento da sua personalidade, os direitos sociais e a justiça distributiva, para cujo atendimento deve se voltar a iniciativa econômica privada e as situações jurídicas patrimoniais (TEPEDINO, 2004, p. 22).

Percebe-se, assim, que os direitos da personalidade se inserem no centro da problemática da queda dos valores "tradicionais" do Direito Privado e da necessidade de uma releitura desse Direito à luz da Constituição, já que a pessoa humana é a maior expressão dos valores complexos com os quais o Direito Civil tem de lidar atualmente, o que demonstra a necessidade, segundo essa doutrina, de uma diretriz constitucional para sua aplicação. Quanto à constitucionalização do Direito Civil, no que concerne aos direitos da personalidade, Tepedino (1999, p. 50) afirma:

A tutela da personalidade - convém, então, insistir - não pode se conter em setores estanques, de um lado os direitos humanos e de outro as chamadas situações jurídicas de direito privado. A pessoa, à luz do sistema constitucional, requer proteção integrada, que supere a dicotomia direito público e direito privado e atenda à cláusula geral fixada pelo texto maior, de promoção da dignidade humana.

Stefano Rodotà (2010) determina como deve se dar essa reinterpretação do direito privado à luz dos princípios constitucionais no âmbito dos direitos da personalidade. O autor afirma que o Código Civil de 2002 representa um retrocesso quanto à tutela da pessoa humana porque não deixa o mais amplo possível o poder de escolha do indivíduo sobre seu corpo, tomando como indicativo disso o artigo 11, que postula serem os direitos da personalidade intransmissíveis e irrenunciáveis (RODOTÀ, 2010, p. 124-125).

Segundo o ponto de vista de Rodotà (2010, p. 126), a tutela da pessoa humana não pode ser feita a partir de alguns artigos pontuais no Código Civil, mas deve se dar "de forma unitária", tendo como base a dignidade humana. Ele defende o uso de uma categoria aberta como essa para proteger a pessoa em detrimento do direito subjetivo, já que o último foi desenhado pensando em relações patrimoniais e não se encaixam na CSOnline - Revista Eletrônica de Ciências Sociais, Juiz de Fora, n. 24 (2017) Dez., pp. 1-309. 
noção de "ser". Sobre a dignidade humana como cláusula constitucional orientadora dos direitos da personalidade, Rodotà (2010, p. 127) afirma:

De fato, oposta a uma identificação taxativa dos direitos da personalidade encontra-se a consideração de que a pessoa humana - e, portanto, sua personalidade - configura um valor unitário, daí decorrendo o reconhecimento, pelo ordenamento jurídico, de uma cláusula geral a consagrar a proteção integral da sua personalidade, isto é, a pessoa globalmente considerada. $\mathrm{O}$ conceito torna-se, então, elástico, abrangendo um número ilimitado de hipóteses, e somente encontra os limites postos na tutela do interesse de outras personalidades.

Coloca-se, assim, o princípio da dignidade da pessoa humana como "cláusula geral de tutela e promoção da personalidade em suas mais diversas manifestações”, não sendo limitável pelo legislador ordinário (RODOTÀ, 2010, p. 128). Cita-se, então, no texto, o Enunciado n. 274 da IV Jornada de Direito Civil (2006, apud RODOTÀ, 2010, p. 129), que diz que

os direitos da personalidade, regulados de maneira não exaustiva pelo Código Civil, são expressões da cláusula geral de tutela da pessoa humana, contida no art. $1^{\circ}$, inciso III, da Constituição (princípio da dignidade da pessoa humana). Em caso de colisão entre eles e como nenhum pode sobrevelar os demais, devese aplicar a técnica da ponderação.

Através dessa citação, é possível perceber que a reinterpretação proposta pelo Direito Civil-constitucional tem força e está sendo aplicada no direito brasileiro. Este artigo, no entanto, não adota essa linha reinterpretativa que tem por base a Constituição. Agora será feita a explicação do porquê dessa escolha.

\section{A crítica ao direito civil-constitucional e ao império da noção de indivíduo}

A aplicação horizontal dos direitos fundamentais e suas consequências para uma reinterpretação dos direitos da personalidade são apenas um dos expoentes de uma corrente de pensamento que vem se desenvolvendo desde a segunda metade do século $\mathrm{XX}$, o neoconstitucionalismo, que visa a estudar as constituições substantivas surgidas após a Segunda Guerra Mundial, estas que regulam de forma mais detalhada o agir estatal e as relações entre indivíduos, pregando ainda a soberania dos princípios dessas Constituições em relação a todo o ordenamento jurídico, de modo que todo ele deve ser (re)interpretado à imagem dela.

Como colocado no tópico anterior, no contexto dos direitos da personalidade, o objetivo dessa interpretação é dar ao indivíduo o maior poder de escolha possível sobre o seu corpo, lançando mão, para isso, da dignidade humana como diretriz interpretativa. $\mathrm{O}$ que se busca, então, é negar a divisão clássica entre direito público e direito privado em sua forma estanque, mitigando o império da autonomia da vontade, dos contratos e das escolhas "livres" feitas sem a intervenção do Estado em detrimento dos princípios constitucionais. Essa é uma tentativa válida de tentar reinterpretar o modo do Estado de CSOnline - Revista Eletrônica de Ciências Sociais, Juiz de Fora, n. 24 (2017) Dez., pp. 1-309. 
tutelar os corpos, mas essa tentativa não se pode lograr efetiva, isso porque ela não problematiza o elemento mais vital à manutenção do controle que o Estado exerce sobre os corpos: a ideia de indivíduo.

Tenta-se romper com os conceitos clássicos do direito privado, mas não se rompe de forma definitiva com o principal deles: a ideia de pessoa entendida como indivíduo. Mesmo que se diga desiludido com a ideia liberal de indivíduo, com a soberania da autonomia da vontade e das "escolhas livres", o foco da reinterpretação Civilconstitucional ainda resta sobre o indivíduo, que é uma noção construída à época do surgimento desse direito liberal e que, por mais que não seja mais entendida essencialmente da mesma maneira, ainda traz em si as categorias problemáticas que Deleuze e Guattari veem nos corpos bloqueados pela tutela opressora de um poder externo: o organismo, a significância e a subjetivação.

Essa noção do indivíduo como o centro da tutela do direito, sujeito de direitos e deveres, aprisiona os corpos e o faz de forma muito problemática, pois, como afirma Vladimir Safatle (2015, p. 19-20), o fato é que a política liberal é desenvolvida no contexto de um

\footnotetext{
"homem novo definido pela procura de seu interesse, pela satisfação de seu amor-próprio e pelas motivações passionais que lhe fizeram agir". Interesses constituídos pelo jogo social de identificações e concorrências, pelo desejo do outro. O que pode nos explicar por que a liberdade tal como compreendida em sociedades cujo modelo de inscrição se dá a partir da determinação de sujeitos sob a forma de indivíduos é paga pela definição do outro como uma espécie de "invasor potencial", como alguém com quem me relaciono preferencialmente através de contratos que definem obrigações e limitações mútuas sob os olhares de um terceiro.
}

A proposição de Safatle deixa claro que essa visão do outro como invasor atua como bloqueador da produção e da passagem de intensidades pelos corpos e entre os corpos, entravando a construção do corpo sem órgãos e, em última instância, do plano de consistência. Esse entrave pode ser explicitado a partir da identificação dos bloqueadores organismo, significância e subjetivação na noção liberal de indivíduo e também na sua reinterpretação Civil-constitucional.

Quanto à ideia de organismo, ela está pressuposta na própria noção de indivíduo. Pode-se dizer que uma reinterpretação à luz da dignidade humana traria mais possibilidades para que se tivessem outras concepções de corpos, mas na verdade o que se permite são modificações pontuais no corpo, não uma nova maneira de compreendêlo. A unidade indivíduo resta praticamente intocada e as relações entre essas unidades continuam sendo limitadas. 
Já em relação à significância, diz-se que ela está presente desde o momento em que se quer tutelar a finalidade dos atos dos indivíduos e interpretar suas vontades até o momento em que se deseja referenciar essa interpretação, já aprisionadora, a algo externo e maior: o texto constitucional. O devir, portanto, não tem espaço na ideia de indivíduo, pois a tutela se baseia em identificar a escolha da pessoa, a finalidade que ela persegue, $o$ que é incompatível com o conjunto constante de práticas constituindo um devir que caracteriza a produção do corpo sem órgãos.

Por último, quanto à subjetivação, entende-se que a noção de indivíduo contém em si a ideia de sujeito de direitos, que, mesmo reformulada um pouco para além das margens liberais, ainda continua acolhendo aquele homem racional iluminista que serviu de modelo para as codificações da modernidade. A reformulação desse conceito pela doutrina civil-constitucionalista só fez romper com a concepção jusnaturalista de que a ideia de sujeito de direitos seria produto de um direito natural, enxergando sua origem em um reconhecimento do direito positivo (TEPEDINO, 1999), mas não rompe com a ideia do sujeito imutável, unidade inviolável e não passível de transformação para além do molde do indivíduo, pronto e acabado para conhecer o mundo, relacionar-se e ter essa atuação estável regulada por um Direito de lógica estruturada e estanque em sua estrutura.

Essa ideia do sujeito como indivíduo acabado surgiu, segundo Foucault (2010, p. 18), no dito "momento cartesiano". Segundo Foucault (2010), na Idade Antiga e no Medievo Ocidental cristão, o sujeito não era visto como apto a conhecer o mundo do modo como se encontrava. A obtenção do conhecimento, destaca o autor, pressupunha uma transformação no sujeito, essa que lhe exigia um esforço. Em compensação, uma vez que o sujeito obtinha o conhecimento, era iluminado por ele, dizendo-se, então que "a verdade salvava o sujeito". Acrescenta-se, ainda, no Medievo, toda uma dimensão divinizada a esse processo de transformação e iluminação do sujeito. A partir do que Foucault chama de "momento cartesiano", no entanto, o sujeito passou a ser enxergado como acabado e pronto a atingir o conhecimento, sendo as únicas exigências para isso a própria coerência interna de seu sistema de obtenção do conhecimento e as condições sociais que o permitissem estudar e desenvolver suas análises. O sujeito não precisava, assim, transformar-se para conhecer a verdade. Em compensação, a verdade não salvava mais o sujeito. É esse sujeito, não transformado e não salvo, que está presente na ideia de indivíduo adotada pelos códigos da Era Moderna e que foi carregado, com modificações pontuais apenas, pela tradição liberal e Civil-constitucional. Esse indivíduo não se abre, 
mas somente se perpetua. Por ele não passam livremente as intensidades que o corpo fizer passar ou produzir, pois ele está bloqueado.

Ressalta-se, ainda, que reinterpretar os direitos da personalidade através dos princípios constitucionais não seria libertar os corpos da restrição, mas sim submetê-los a uma restrição externa, feita por uma Constituição que não é um texto verdadeiramente acolhedor da multiplicidade, já que ela é baseada na reprodução binária de conceitos e nas leis do Uno, só acolhendo o que cabe nessa "estrutura" de reprodução dicotômica (HOFFMANN, 2017, p. 3). O texto relacionado aos direitos da personalidade se transforma, então, naquilo que Deleuze e Guattari (1995, p. 14) chamam livro de raiz fasciculada, em que se abole a raiz principal, mas ainda há raízes secundárias que ficam desnorteadas e restritas por algo maior que elas, como afirmam os autores:

o sistema fasciculado não rompe verdadeiramente com o dualismo, com a complementaridade de um sujeito e de um objeto, de uma realidade natural e de uma realidade espiritual: a unidade não pára de ser contrariada e impedida no objeto, enquanto que um novo tipo de unidade triunfa no sujeito. $\mathrm{O}$ mundo perdeu seu pivô, o sujeito não pode nem mesmo mais fazer dicotomia, mas acede a uma mais alta unidade, de ambivalência ou de sobredeterminação, numa dimensão sempre suplementar àquela de seu objeto (DELEUZE; GUATTARI, 1995, p. 14).

Compreende-se, assim, porque, num primeiro momento, uma remissão à Constituição não é uma boa solução para o engessamento dos corpos provocados pelos direitos da personalidade. A libertação dos corpos e a produção do corpo sem órgãos deve se dar, então, por um conjunto de práticas constantes de desfazimento da subjetivação, da significância e do organismo, num processo que é devir e não busca um fim.

O que o Estado poderia fazer pelos corpos, se a insistência é tanta em tutelá-los, seria permitir a livre produção e circulação de intensidades neles e entre eles. Dessa forma eles serão efetivamente múltiplos. Conforme diz Tomaz Tadeu (2009, p. 14) em seu texto Nós, ciborgues, o que se deve fazer em relação aos corpos é não pensar o mundo em termos de sujeitos, e sim em termos de fluxos e de intensidades. Estes seriam os elementos primários, que encontrariam, durante suas passagens, aqueles, os quais seriam vistos, então, como elementos secundários em relação aos fluxos.

E como pode o corpo, então, resistir e desfazer o organismo no cenário em que vivemos? Pouco a pouco, isso é fato, guardando ainda, como já se mencionou na exposição do pensamento de Deleuze e Guattari, pequenas partes do organismo para continuar vivendo e enfrentar o sistema vigente. David Lapoujade (2011) defende que o corpo crie mecanismos de defesa, endurecendo-se em relação ao exterior de modo a se proteger dos ataques e a que as feridas pequenas passem a não ter importância nenhuma. 
O corpo poderá, então, segundo o autor, expor-se no interior desse fechamento, e ali resistir e se desestratificar enquanto resiste. A proposta do autor é interessante, pois permite que a produção do corpo sem órgãos aconteça de maneira prudente, como indicam que deve ser Deleuze e Guattari.

Por fim, analisa-se a questão de se o texto constitucional, já que não pode ser "paradigma reinterpretador" dos direitos da personalidade, pode ter alguma serventia à produção do corpo sem órgãos. O que se encontra por resposta é um chamado. Deleuze e Guattari $(1995$, p. 24; 31) dizem que os livros que obedecem à lógica do Uno têm em si “deformações anárquicas", que podem ser utilizados para criar a partir delas um terceiro tipo de livro, o livro rizoma, que não obedece à lógica de reprodução binária e é efetivamente acolhedor da multiplicidade.

Vê-se, assim, alguma utilidade na busca dessas deformações, apesar de os autores de Mil Platôs afirmarem, em relação à criação do plano de consistência, conjunto de todos os corpos sem órgãos, que:

o problema não é mais aquele do Uno e do Múltiplo, mas o da multiplicidade de fusão, que transborda efetivamente toda oposição do uno e do múltiplo. Multiplicidade formal dos atributos substanciais que constitui como tal a unidade ontológica da substância (DELEUZE; GUATTARI, 1996, p. 15).

Entende-se, portanto, que a busca por linhas de fuga para explodir rizoma nos livros raiz e raiz fasciculada é pressuposto da produção plena do conjunto de todos os corpos sem órgãos. O que acontece, todavia, é que, na sociedade atual, ainda não foi superada a oposição entre o Uno e o Múltiplo para que se passe a tentativas efetivas de produção do plano de consistência. É possível, claro, praticar a produção do corpo sem órgãos, mas a presença forte da lógica binária na atualidade traz consigo bloqueadores que dificultam muito a plenitude desse processo. Nesse contexto, o chamado que se coloca é à busca de deformações no texto da Constituição que permitam criar a partir dela, um rizoma, acolhedor efetivo da multiplicidade, que produza um contexto mais favorável a um avanço seguro da desestratificação dos corpos e à formação do corpo sem órgãos. É só desse modo que se pode buscar a libertação dos corpos da tutela opressiva dos poderes hegemônicos através do texto constitucional.

\section{Conclusão}

O intuito deste artigo foi o de analisar o regime atual dos direitos da personalidade no ordenamento jurídico brasileiro, seja na forma como estão positivados no Código Civil, seja na reinterpretação proposta pelo Direito Civil-constitucional, de modo a problematizar mais amplamente essa regulação a partir de um marco teórico que 
não tenha apego à tradição e nem naturalize ou tente esgarçar categorias jurídicas para interpretá-las sem correr o risco de precisar romper com elas.

Dessa maneira, primeiramente foram introduzidas algumas noções foucaultianas sobre corpo e poder, para logo após ser apresentado o marco teórico utilizado: o pensamento de Gilles Deleuze e Félix Guattari quanto ao corpo sem órgãos. Em seguida, foi feita uma exposição sobre a situação atual dos direitos da personalidade no Código Civil de 2002, atualmente em vigor no ordenamento jurídico brasileiro. Logo após foi colocada a crítica do chamado Direito Civil-constitucional ao modelo vigente no Código Civil e a reinterpretação do regime de direitos da personalidade proposta por essa corrente a partir da Constituição de 1988. Por fim, criticou-se a proposta Civil-constitucional, principalmente através da problematização da categoria indivíduo e da não eficácia do texto constitucional em acolher a multiplicidade, propondo-se um outro modo de enxergar as coisas, em que os fluxos se colocam como principais em relação aos indivíduos.

A proposta final do artigo está em dois âmbitos: primeiramente, no âmbito do corpo, que deve buscar sempre a sua desestratificação pela retirada da significância, da subjetivação e do organismo; além disso, há o âmbito do texto da Constituição, no qual deve ser constante a busca por "deformações anárquicas" que permitam a criação de algo efetivamente acolhedor da multiplicidade. Deixa-se, aqui, o gancho para pesquisas futuras, tanto de formas de desestratificação dos corpos como de momentos na Constituição que podem ser utilizados para encontrar um movimento que levará a uma realidade acolhedora do Múltiplo.

\section{Referências}

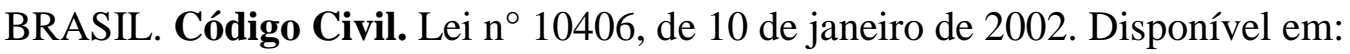
<http://www.planalto.gov.br/ccivil_03/leis/2002/L10406.htm>. Acesso em: 25 jun. 2017.

DELEUZE, Gilles; GUATTARI, Félix. Mil platôs: capitalismo e esquizofrenia, vol.1. São Paulo: Ed. 34, 1995.

Mil platôs - capitalismo e esquizofrenia, vol. 3. São Paulo: Ed.

34, 1996.

FOUCAULT, Michel. A Hermenêutica do Sujeito. Curso dado no Collège de France (1981-1982). São Paulo: Martins Fontes, 2010.

Em defesa da sociedade. Curso dado no Collège de France (1975-1976). $1^{\text {a }}$ Edição. São Paulo: Martins Fontes, 1999. (Coleção tópicos) 
. Microfísica do poder. Rio de Janeiro: Edições Graal, 1979.

HOFFMANN, Caio. A Constituição como raiz e a justiça como rizoma: uma análise do texto constitucional enquanto livro. Anais da II Semana Jurídica do DABC. No prelo.

LAPOUJADE, David. O corpo que não aguenta mais. 29 abr. 2011. Revista Polichinelo. Disponível em: <https://revistapolichinelo.blogspot.com.br/2011/04/ocorpo-que-nao-aguenta-mais.html>. Acesso em: 5 ago. 2017.

MENDES, Cláudio Lúcio. O corpo em Foucault: superfície de disciplinamento e governo. Revista de Ciências Humanas, Florianópolis, EDUFSC, n. 39, p. 167-181, Abril de 2006.

RODOTÀ, Stefano. Ampliando os direitos da personalidade. In: MORAES, Maria Celina Bodin de. Na medida da pessoa humana: estudos de direito civil. Rio de Janeiro: Renovar, 2010.

SAFATLE, Vladimir. O circuito dos afetos. São Paulo: Cozac Nayif, 2015. SILVA, Denis Franco. Teoria Geral do Direito Privado. 5 out. 2016. 4f. Notas de Aula. Manuscrito.

TADEU, Tomaz (Org.). Antropologia do ciborgue: as vertigens do pós-humano. Belo Horizonte: Autêntica Editora, 2009.

TEPEDINO, Gustavo. A Tutela da Personalidade no Ordenamento Civilconstitucional Brasileiro. In: TEPEDINO, Gustavo. Temas de Direito Civil. Rio de Janeiro: Renovar. 1999.

Premissas Metodológicas para a Constitucionalização do Direito Civil. Rio de Janeiro: Renovar, 2004. 